\title{
PENINGKATAN PRODUKSI BENIH LELE, PERBAIKAN PAKAN PADA PEMBUDIDAYA LELE SUDI LESTARI, DESA BANDARAN, KABUPATEN PASURUAN
}

\author{
Pungky Slamet WK ${ }^{1)}$, Dyah Hariani²) \\ ${ }^{1}$ Department of Biology, Faculty of Mathematics and Natural Sciences, Universitas PGRI Adi Buana, Jalan \\ Ngagel Dadi IIIB/37 Wonokromo, Surabaya 60245, East Java, INDONESIA \\ ${ }^{2}$ Department of Biology, Faculty of Mathematics and Natural Sciences, Universitas Negeri Surabaya, Jalan \\ Ketintang Wiyata No. 48, Gayungan, Surabaya 60231, East Java, INDONESIA \\ Email:dyahhariani@unesa.ac.id
}

\begin{abstract}
Abstrak
Permasalahan yang dihadapi mitra tingginya harga pakan ikan dari pabrik, hal ini menyebabkan keuntungan dari usahannya sangat rendah. Pengadaan benih lele masih membeli dari daerah lain dan tidak selalu memenuhi jumlah yang dipesan. Hal ini menyebabkan kolam tidak semua terisi, sehingga pendapatannya tidak kontinyu. Selain itu para pembudidaya ikan kebanyakan belum dapat membenihkan sendiri. Untuk itu perlu adanya upaya melalui program kemitraan masyarakat agar para pembudidaya ikan lele Sudi Lestari Dusun Kampung Baru, Desa Bandaran, Kec.Winongan, Kab. Pasuruan mampu membenihkan ikan sendiri untuk memenuhi kebutuhan benih yang selama ini membeli dari luar desa. Penyelesaian permasalahan mitra diatasi dengan beberapa cara : Pertama melalui program pelatihan dan pendampingan tentang teknologi tepat guna laserpunktur untuk mempercepat induk lele matang gonad. Kedua melalui pelatihan dan pendampingan tentang pembuatan pakan formula probiotik untuk mempersiapkan induk lele matang gonad siap dipijahkan guna mempercepat pengadaan benih. Hasil pelatihan dan pendampingan ini pengetahuan masyarakat pembudidaya ikan lele meningkat karena yang dilatihkan ini merupakan teknologi baru dan pembudidaya merasakan puas karena dapat mempersiakan induk lele matang gonad siap dipijahkan untuk menghasilkan benih yang berkualitas dan benih lele tersedia setiap saat serta hemat pakan. Diharapkan kedepan mampu meningkatkan pendapatan dan kesejahteraan pembudidaya ikan lele disekitar desa dan diluar desanya.
\end{abstract}

Kata kunci : Pelatihan, Laserpunktur dan Perbaikan Pakan Lele

\begin{abstract}
The problem faced by partners is the high price of fish feed from the factory, this causes the profits from their businesses to be very low. Catfish seed procurement is still bought from other regions and does not always meet the amount ordered. This causes the pond is not all filled, so the income is not continuous. In addition, most fish farmers cannot yet self-fertilize. For this reason, efforts are needed through community partnership programs so that Sudi Lestari Dusun Kampung Baru, Desa Bandaran, Kec.Winongan, Kab. Pasuruan is capable of hatching its own fish to meet the needs of seeds that have been bought from outside the village. Resolving partner issues is overcome in a number of ways: First through a training program and mentoring on laserpuncture appropriate technology to accelerate mature gonad catfish. Second, through training and mentoring on making probiotic formula feed to prepare mature gonad catfish brooders ready for breeding to accelerate seed procurement. The results of this training and mentoring community knowledge increased catfish because it is a trained new technology and cultivator feel satisfied because it can get the mother of ripe catfish ready to be presented to produce quality seed and
\end{abstract}


catfish available at any time and save the feed. Expected to be able to increase the income and prosperity of the catfish farmers around the village.

Keywords: Training, Laserpuncture and Catfish Feed Repair

\section{PENDAHULUAN}

Dusun Kampung Baru, Desa Bandaran, Kec.Winongan, Kab. Pasuruan Propinsi Jawa Timur merupakan wilayah yang akan digunakan dalam Program Kemitraan Masyarakat (PKM) tahun anggaran 2019 sebagai pilot projek yang diharapkan akan diikuti oleh kecamatankecamatan lain. Desa Bandaran ini dipilih sebagai tempat pelaksanaan PKM dikarenakan memiliki beberapa keunggulan, antara lain : 1) potensi budidaya ikan air tawar sangat besar, 2) hampir semua penduduk memiliki mata pencaharian utama pertanian disamping usaha lainnya seperti budidaya ikan, 3) potensi lahan budidaya sangat besar dengan luasnya areal atau kolam yang dimiliki masyarakat, 4) ratarata satu kelompok punya 10 kolam yang dikelola dalam satu lokasi 5) kolam budidaya ikan lele dengan ukuran kolam $12 \times 9 \mathrm{~m}^{2}$ ada 1 kolam, ukuran $8,5 \times 6,5 \mathrm{~m}^{2}$ ada 1 kolam, 9x1,5 $\mathrm{m}^{2}$ ada 4 kolam, $2,5 \times 4 \mathrm{~m}^{2}$ ada 3 kolam dan $5,5 \times 8 \mathrm{~m}^{2}$ ada 1 kolam, 5) sumber air tawar yang diperoleh dari sumur bor artetis sehingga air tersedia sepanjang tahun, 6) kualitas air sesuai untuk budidaya ikan, 7) air yang digunakan untuk budidaya ikan tidak ada pencemaran terhadap kualitas air dari limbah pabrik yang membahayakan untuk budidaya ikan, 8) pengetahuan masyarakat pembudidaya ikan relatif cukup dan 9) potensi minat serta keingintahuan masyarakat pembudidaya terhadap perkembangan ilmu budidaya ikan sangat tinggi.

Kondisi potensi sumber daya air di
desa Bandaran yang mempunyai ketersediaan air irigasi yang cukup di hitung berdasarkan volume debiet dan area yang dialiri mempunyai potensi unggulan seperti untuk: pembenihan ikan nila dan lele. Hal ini dapat dilihat dari kondisi ketersediaan air yang memadai dan faktor lahan yang juga ditunjang oleh tenaga pemuda yang handal sehingga dengan pemberian pelatihan dan pendampingan ini diharapkan mampu meningkatkan pendapatan dan kesejahteraan masyarakat petani. Sedangkan permasalahan utama yang dihadapi oleh para pembudidaya lele di desa Bandaran ini cara budidayanya masih konvensional, lele setelah memijah memerlukan recovery untuk dapat memijah kembali membutuhkan waktu sekitar 3 bulan kemudian, dengan demikian ketersediaan benih lele tidak banyak dan tidak kontinyu, secara langsung maupun tidak langsung dapat menghambat produktivitas usaha budidaya lele itu sendiri. Penerapan teknologi tepat guna untuk pengembangan usaha budidaya, khususnya pembenihan lele belum tersebar secara merata pada pembudidaya lele dan kalaupun ada mungkin sudah terlambat dan merupakan teknologi lama yang telah banyak digunakan. Untuk itu perlu dicari solusinya dengan cara mencari terobosan teknologi tepat guna yang dapat mempercepat pengadaan induk lele matang gonad siap dipijahkan untuk menghasilkan benih yang berkualitas. Teknologi tepat guna yang dimaksud adalah teknologi laserpunktur dan perbaikan pakan untuk induk lele. Pemanfaatan soft laser sudah diaplikasikan dalam penelitian Kusuma (2002) menunjukkan bahwa teknologi laserpunktur terbukti dapat mempercepat induk matang gonad dan memperpendek siklus reproduksi ikan nila. Induk ikan nila yang diinduksi soft laser He-Ne tepatnya di $2 / 3$ bagian ventral tubuh selama 6 detik setiap seminggu sekali terbukti induk ikan nila cepat matang gonad dan induk siap dipijahkan, sedangkan dalam kondisi normal, induk 
ikan nila matang gonad setiap 1-2 bulan sekali.

Selanjutnya Kusuma dkk (2007; 2009) mengaplikasikan pada induk lele yang diinduksi soft laser $\mathrm{He}-\mathrm{Ne}$ tepatnya di $1 / 3$ bagian ventral tubuh selama 15 detik setiap seminggu sekali. Dari hasil penelitian menunjukkan bahwa induk lele cepat matang gonad dan siap untuk dipijahkan guna mempercepat produksi benih lele. Dari kedua hasil peneliti ini perlu dilakukan sosialisasi tentang teknologi laserpunktur dan perbaikan pakan sebagai upaya untuk mempercepat produksi benih lele di Dusun Kampung Baru, Desa Bandaran, Kec.Winongan, Kab. Pasuruan Propinsi Jawa Timur, setiap saat dalam jumlah yang banyak dan kontinyu.

Pemijahan induk lele secara konvensional dalam satu tahun biasanya satu induk dapat memproduksi benih sekitar 3-4 kali, maka dengan menggunakan teknologi laserpuktur satu induk dapat menghasilkan benih lele sampai 6-8 kali. Berdasarkan hasil penelitian di lapangan di daerah Boyolali (2007), Pare Kediri (2010; 2012), Gresik (2013) maupun di daerah Cangkringturi (2017), biasanya induk lele yang dipijahkan mengeluarkan telurnya secara bertahap dan tidak semuanya dikeluarkan dalam satu kali pemijahan, maka dengan menggunakan teknologi laserpunktur ini keseluruhan telur matang di ovarium dikeluarkan untuk dibuahi oleh sperma dan akhinya menetas menjadi benih dapat mencapai sekitar 80$90 \%$. Hasil penenerapan teknologi laserpunktur inilah yang selanjutnya akan diaplikasikan ke daerah lain.

Hasil penelitian ini selanjutnya disebarluaskan melaui pendekatan kepada salah satu ketua kelompok pembudidaya le 1 e Sudi Lestari di Desa Bandaran yang nantinya merupakan salah satu target sasaran strategis untuk memberikan sosialisasi awal dan untuk diterapkan di kolam miliknya. Menurut informasi dari ketua kelompok Sudi Lestari pembenih lele di Desa Bandaran budidaya yang selama ini bergerak di pembesaran ikan lele belum menghasilkan sesuai yang diharapkan dan sering merugi. Hal inilah yang menarik untuk ditindak lanjuti, masalah teknologi budidaya masih kurang dikuasahi, pembudidaya berkeinginan dapat membenihkan lele sendiri karena selama ini benih lele dibeli dari Kediri dan Blitar. Untuk mengatasi permasalahan tersebut dapat dipenuhi dengan teknologi laserpunktur dan perbaikan pakan untuk pematangan gonad dan rangsang pemijahan induk lele yang dibudidaya.

Diharapkan teknologi leserpunktur dan perbaikan pakan untuk induk ini dapat membantu pembudidaya dalam mempercepat pengadaan induk $1 \mathrm{e} 1 \mathrm{e}$ matang gonad dan siap dipijahkan guna memproduksi benih yang banyak dan kontinyu, karena induk lele dapat memijah secara optimal. Penerapan IPTEKS melalui Program Kemitraan Masyarakat (PKM) tahun anggaran 2019 secara berkelanjutan agar mitra pembudidaya lele yang dibina ini dapat meningkatkan produktivitas dan mengembangkan usaha yang pada gilirannya kelompok pembudidaya lele ini dapat meningkatkan kesejahteraannya serta dapat menyerap tenaga kerja baru di sekitarnya.

Akhir dari pelatihan dan pendampingan Program Kemitraan Masyarakat (PKM) tahun anggaran 2019 ini Dusun Kampung Baru, Desa Bandaran dapat mempersiapkan tentang tata cara untuk mempercepat pengadaan induk matang gonad guna memproduksi benih lele sediri selain itu juga dapat mensuplai benih lele diluar desanya, akibatnya pendapatan kelompok pembudidaya Sudi Lestari dapat meningkatkan penghasilannya.

\section{METODE PELAKSANAAN Waktu dan Tempat Pengabdian}

Waktu pelaksanaan bulan 6 Juli sampai dengan 3 Agustus 2019. Peserta pelatian adalah kelompok pembudidaya lele Sudi Lestari yang telah berpengalaman maupun belum dari Dusun Kampung Baru, Desa Bandaran dengan jumlah keseluruhan 
peserta sebanyak 20 orang pembudidaya lele Kegiatan pelatihan dan pendampingan ini difokuskan pada sosialisasi teknologi laserpunktur dan perbaikan pakan induk lele terintegrasi melalui pendekatan teori dan praktek. Teori dalam arti konsep teknologi laserpunktur dan perbaikan pakan untuk mempercepat induk lele matang gonad siap dipijahkan guna menghasilkan benih yang banyak dan kontinyu yang diterapkan berdasarkan pada pengkajian secara ilmiah dari hasil penelitihan, sedangkan praktek atau aplikasinya sampai dihasilkannya benih lele semua ini dilakukan oleh pembudidaya lele itu sendiri.

\section{Metode Pelaksanaan}

Pelaksanaan kegiatan pelatihan dan pendampingan ini difokuskan pada pelatihan tentang teknologi laserpunktur dan perbaikan pakan sebagai upaya mempercepat induk lele matang gonad siap dipijahkan untuk memproduksi benih sekala massal pada kelompok pembudidaya lele di Dusun Kampung Baru, Desa Bandaran. Dengan memberikan dempond dan pendampingan kepada kelompok pembudidaya lele sebagai mitra binaan. Dalam upaya pemecahanan masalah pengadaan induk matang gonad dan benih meliputi tahap-tahap seperti berikut dibawah ini :

1. Penggalangan peserta kelompok pembenih lele yang telah berpengalaman maupun belum dari Dusun Kampung Baru, Desa Bandaran dengan jumlah keseluruhan peserta sebanyak 20 orang pembudidaya lele.

2. Mempersiapkan segala sesuatu yang berkaitan dengan kegiatan pelatihan dan pendampingan dalam sosialisasi teknologi laserpunktur dan perbaikan pakan untuk mempercepat induk lele matang gonad dan produksi benih.

3. Pelaksanaan pelatihan dan pendampingan teknologi laserpunktur dan perbaikan pakan dalam kegiatan ini dilakukan di salah satu rumah milik ketua kelompok pembudidaya lele (Bapak Agus Suprianto) di Dusun Kampung Baru, Desa Bandaran. Dilakukan dengan cara dempond dan hasilnya dapat dilihat dan dipraktekan di kolam nasing-masing peserta pelatihan dan pendampingan.

4. Pendampingan ke setiap pembenih lele yang telah mengikuti pelatihan tentang teknologi laserpunktur dan perbaikan pakan untuk mengaplikasikannya dan membuat report tentang produksi benih lele yang dihasilkan serta hasil penjualan benih sampai pelaksanaan PKM berakhir. Alternatif tersebut diambil dengan pertimbangan efisiensi dan efektivitas pencapaian tujuan dalam kegiatan ini. Kegiatan pelatihan dan pendampingan untuk sosialisasi teknologi laserpunktur dan perbaikan pakan ini terintegrasi melalui pendekatan teori dan praktek.

5. Teori dalam arti konsep teknologi laserpunktur dan perbaikan pakan guna mempercepat induk lele matang gonad siap dipijahkan dan mempercepat produksi benih lele, diterapkan berdasarkan pada hasil pengkajian secara ilmiah hasil penelitian, sedangkan praktek atau aplikasinya sampai dihasilkannya benih semua ini dilakukan oleh pembudidaya lele itu sendiri.

6. Didalam memberikan pelatihan pada kelompok pembudidaya lele agar para peserta yang ikut dalam pelatihan dapat melakukan sendiri tetang aplikasi induksi pada titik reproduksi dengan tepat, trampil mengoperasikan laserpunktur pada induk lele di kolam masing-masing guna mempercepat induk matang gonad dan siap dipijahkan untuk memproduksi benih. Sedangkan hasil kegiatan dan respon peserta pelatihan dan pendampingan dapat dilihat pada tabel 1 berikut ini : 
Tabel 1. Jenis kegiatan dan respon pembudidaya lele setelah mendapatkan teori dan praktek

\begin{tabular}{|c|c|c|}
\hline No. & Jenis Kegiatan & Respon \\
\hline 1 & $\begin{array}{lr}\text { Ceramah dan tanya } \\
\text { jawab tentang } \\
\text { apakah } \\
\text { laserpunktur kepada } \\
\text { peserta pelatihan }\end{array}$ & $\begin{array}{l}\text { Semua } \\
\text { peserta } \\
\text { mengikuti } \\
\text { dan sesekali } \\
\text { ada tanya } \\
\text { jawab dari } \\
\text { peserta } \\
\text { pelatihan }\end{array}$ \\
\hline 2 & $\begin{array}{l}\text { Pengenalan unit } \\
\text { laserpunktur dan } \\
\text { cara } \\
\text { menggunakannya } \\
\text { oleh tim PKM. }\end{array}$ & $\begin{array}{l}\text { Peserta } \\
\text { tertarik } \\
\text { dengan teknik } \\
\text { reproduksi } \\
\text { baru untuk } \\
\text { rangsang } \\
\text { pematangan } \\
\text { gonad dan } \\
\text { pemijahan }\end{array}$ \\
\hline 3 & $\begin{array}{l}\text { Demonstrasi } \\
\text { tentang cara induksi } \\
\text { laserpunktur pada } \\
\text { titik reproduksi } \\
\text { induk lele oleh tim } \\
\text { PKM. }\end{array}$ & $\begin{array}{l}\text { Peserta } \\
\text { pelatian } \\
\text { antusias } \\
\text { ditunjukkan } \\
\text { sampai akhir } \\
\text { pelatian ini } \\
\text { tidak ada } \\
\text { peserta yang } \\
\text { yang } \\
\text { meninggalkan } \\
\text { pelatihan }\end{array}$ \\
\hline 4 & $\begin{array}{l}\text { Setiap peserta } \\
\text { diberikan } \\
\text { kesempatan untuk } \\
\text { mempraktekkan } \\
\text { sendiri cara induksi } \\
\text { laserpunktur pada } \\
\text { ikan lele di titik } \\
\text { reproduksi dengan } \\
\text { tepat dan cara } \\
\text { mengoperasikan } \\
\text { laserpunktur dengan } \\
\text { benar. }\end{array}$ & $\begin{array}{l}\text { Setelah } \\
\text { diberikan } \\
\text { cotoh cara } \\
\text { penggunaan } \\
\text { laserpunktur } \\
\text { peserta } \\
\text { pelatihan } \\
\text { dapat } \\
\text { melakukan } \\
\text { dengan benar }\end{array}$ \\
\hline 5 & $\begin{array}{l}\text { Dempond di kolam } \\
\text { ketua kelompok } \\
\text { pembudidaya lele } \\
\text { desa Kampung }\end{array}$ & $\begin{array}{l}\text { Demplot } \\
\text { dilakukan di } \\
\text { ketua } \\
\text { kelompok }\end{array}$ \\
\hline
\end{tabular}

Baru

dengan tujuan apabila

pelatihan ini berhasil akan

diikuti oleh anggata

kelompok bahkan dari segi positipnya dapat di informasikan ke teman pembudidaya lele di lain desanya

6

Aplikasi teknologi laserpunktur $\mathrm{p}$ a d a pembudidaya ikan lele di kolam masing-masing peserta pelatihan
Aplikasi hasil pelatihan di lakukan dikolam masingmasing peserta ini diharapkan apa yang telah dijelaskan terbukti benar

\section{HASIL DAN PEMBAHASAN}

Partisipasi mitra dalam pelaksanaan program pelatihan dan pendampingan ini dapat mengikuti sosialisasi program dan memberikan data (jawaban) yang akan dipergunakan untuk kepentingan kegiatan pelaksanaan seperti fasilitas penyediaan tempat, alat dan bahan serta dempond yang digunakan dalam sosialisasi Program Kemitraan Masyarakat (PKM) ini. Pada tahap ini pembudidaya lele sebagai kelompok sasaran diharapkan berperan aktif pada :

a) Partisipasi dalam penyediaan kolam lele untuk dempond, kelompok peserta pelatihan dengan senang membolehkan kalomnya yang saat itu kosong dipakai untuk pelatihan aplikasi induksi laserpunktur dan perbaikan pakan 
untuk pematangan gonad dan rangsang pemijahan induk lele.

b) Partisipasi kelompok sasaran untuk mengikuti pelatihan semua peserta tertarik dengan pelatihan ini namun mereka tidak mau coba-coba dengan teknik baru ini sebaiknya kata salah satu anggota kelompok akan melihat dulu hasilnya, setelah tahu hasilnya ada dari peserta dalam kelompok yang mau mencoba dan berhasil serta mengaplikasikan hasil pelatihan sampai sekarang untuk mempercepat pematangan gonad dan rangsang pemijahan terbukti dari hasil pemijahan telur yang dihasilkan dan terbuahi menetas dan menyebar secara merata di kolam pemijahan dengan keberhasilan telur yang menetas menjadi larva sekitar $90 \%$. Setelah mengetahui ada anggota kelompok yang berhasil memijahkan dengan teknologi laserpunktur dan hasilnya baik baru ada anggota kelompok yang lain mencobanya.

c) Partisipasi peserta pelatihan dalam mempraktekkan induksi laserpunktur dan perbaikan pakan pada induk lele di kolam masing-masing antusias. Namun ada beberapa peserta yang tidak melakukan dan mereka beranggapan bahwa dengan kawin alami dengan mengunakan induk berkualitas bagus serta pakan yang bagus sudah menguntung. Tapi setelah mengetahui ada anggota yang berhasil memijahkan dengan teknologi laserpunktur dan hasilnya baik baru ada anggota lain yang mencobanya dan berhasil ditunjukkan induk lele yang diinduksi laserpunktur memijah dengan hasil yang memuaskan yang awalnya tanpa perlakuan induksi laserpunktur dari satu ekor induk lele dengan bobot badan $1 \mathrm{~kg}$ cuma menghasilkan benih sampai ukur 12 cm sebanyak 32964 ekor, setelah menggunakan induksi laserpunktur dapat menghasilkan benih sampai ukur 1-2 cm sebanyak 62268 ekor ada selisih 29304 ekor benih, inilah keuntungannya pemakaian induksi laserpunktur bila dibandingkan dengan kawin alam tanpa induksi laserpunktur.

d) Partisipasi kelompok sasaran untuk membuat laporan tentang data produksi benih lele hasil induksi laserpunktur dan perbaikan pakan dan data hasil penjualan juga dibandingkan dengan produksi benih lele dan hasil penjualan benih yang dihasilkan sebelum menggunakan teknologi laserpunktur.

e) Partisipasi kelompok sasaran antusias untuk membantu pelaksanaan monitoring dari Tim Penyelenggara Program Kemitraan Masyarakat (PKM).

f) Partisipasi kelompok sasaran antusias untuk bekerjasama dalam penyediaan broodstock (induk lele matang gonad) dan pemasaran benih lele untuk mencari pangsa pasar yang lebih luas.

\section{DAMPAK DAN MANFAAT KEGIATAN}

Berdasarkan hasil wawancara dengan ketua kelompok pembudidaya lele Dusun Kampung Baru, Desa Bandaran, diperoleh informasi bahwa induksi laserpunktur dan perbaikan pakan terbukti dapat mempercepat induk lele matang gonad siap dipijahkan untuk menghasilkan benih lele yang berkualitas, selain itu ketua kelompok juga mengatakan bahwa pemakaian induksi laserpunktur dan perbaikan pakan pada induk lele dapat meningkatkan jumlah induk matang gonad siap untuk dipijahkan jumlahnya banyak dibandingkan tanpa mengunakan induksi laserpunktur dan perbaikan pakan induk. Walaupun tidak dilakukan pengukuran secara kuantitatif, namun pembudidaya lele dapat merasakan keuntungan langsung manfaat dan dampak positif dari penerapan teknologi induksi 
dengan pemijahan alam tanpa induksi laserpunktur dan perbaikan pakan benih yang dihasilkan sedikit dan kurang menguntungkan beralih ke teknologi baru yang disosialisasikan tim PKM, dimana hasil aplikasi teknologi laserpunktur dan perbaikan pakan ini benih yang dihasilkan banyak dapat mencukupi kebutuhan benih untuk dibesarkan sendiri serta dapat menjual benih ke luar daerahnya.

antusias untuk mengaplikasikan pada induk lele yang ada pada kolam masing-masing pembudidaya lele.

Dimana ditunjukkan induk lele yang diinduksi laserpunktur dan perbaikan pakan terbukti induk lele yang dibudidaya lebih cepat matang gonad dan segera memijah dengan hasil yang memuaskan, dimana yang awalnya tanpa perlakuan induksi laserpunktur dan perbaikan pakan dari satu ekor induk lele matang gonad dengan bobot badan $1 \mathrm{~kg}$ hanya dapat menghasilkan benih sampai ukur 1-2 cm sebanyak 32964 ekor, setelah menggunakan induksi laserpunktur dan perbaikan pakan dapat menghasilkan benih sampai ukur $1-2 \mathrm{~cm}$ sebanyak 62268 ekor ada selisih 29304 ekor benih, inilah keuntungan yang diperoleh dari pemakaian induksi laserpunktur dan perbaikan pakan untuk mempercepat induk lele matang gonad siap dipijahkan bila dibandingkan dengan kawin alam tanpa induksi laserpunktur dan perbaikan pakan induk lele.

\section{KESIMPULAN}

a) Pelaksanaan kegiatan pelatihan dan pendampingan tentang teknologi laserpunktur dan perbaikan pakan induk sebagai upaya mempercepat induk lele matang gonad siap dipijahkan pada kelompok pembudidaya lele di Dusun Kampung Baru, Desa Bandaran. Telah terbukti dan pembudidaya lele diuntungkan ditunjukkan adanya peningkatan produksi benih lele yang dihasilkan dari pemijahan induk.

b) Masyarakat pembudidaya lele diuntungkan karena selama ini

\section{UCAPAN TERIMAKASIH}

Pelaksanaan pelatihan dan
pendampingan tentang teknologi laserpunktur dan perbaikan pakan sebagai upaya mempercepat induk lele matang gonad siap dipijahkan pada kelompok pembudidaya lele di Dusun Kampung Baru, Desa Bandaran ini tidak terlepas dari peran kerjasama berbagai pihak, antara lain Pimpinan Universitas PGRI Adi Buana Surabaya serta Mitra dalam hal ini ketua kelompok pembudidaya lele Sudi Lestari Bapak Agus Suprianto yang telah memberikan kesempatan dalam kegiatan PKM ini.

\section{REFERENSI}

Kusuma PSW, 2002. Optimalisasi Letak Titik dan Frekuensi Penembakan Laserpuncture (He-Ne) terhadap GSI Ikan Nila (Oreochromis sp), Karya ilmiah.

Dyah Hariani dan Kusuma PSW. 2017. Percepatan Pemijahan Lele Dengan Induksi Laserpunktur Untuk Memproduksi Benih Sekala Massal. Jurnal Pengabdian Masyarakat. UNTAG Surabaya.

Dyah Hariani dan Kusuma PSW. 2009. Biostimuli Reproduksi Ikan Lele Dumbo (Clarias gariepinus) Betina dengan Penembakan Laserpunktur. Jurnal berkala penelitian Hayati. Edisi Khusus.

Dyah Hariani dan Kusuma PSW.2007. Aplikasi Teknologi Laser Untuk Peningkatan Produksi Lele dalam Rangka Pengembangan Ekonomi 
Masyarakat Desa Di Kabupaten Boyolali Jawa Tengah. Dana LP2M Provinsi Jateng.

Dyah Hariani, Kusuma PSW dan Maheno.2010. Pemberdayaan

Kelompok Pembenih Lele Untuk Peningkatan Produksi Benih Menggunakan Laserpunktur Sebagai Upaya Peningkatan Pendapatan Di Desa Krecek, Kec. Pare, Kab. Kediri . Dana DP2M (Ketua).

Kusuma PSW, Indah Nurhayati dan Sriwidiastuti. 2012. Pemanfaatan Limbah Pertanian dan Peternakan Untuk Pembuatan Pakan Ikan Probiotik Pada Budidaya Lele Organik Guna Meningkatkan Pendapatan Peternak Lele. Dusun Nepen Desa Krecek Kecamatan Badas Kabupaten Kediri, Provinsi Jawa Timur. 